\title{
Inflation and inflation uncertainty: A dynamic framework
}

\author{
M. Hakan Berument ${ }^{\mathrm{a}, *}$, Yeliz Yalcin ${ }^{\mathrm{b}, 1}$, Julide Yildirim ${ }^{\mathrm{c}, 2}$ \\ a Department of Economics, Bilkent University, 06800 Ankara, Turkey \\ ${ }^{\mathrm{b}}$ Department of Econometrics, Gazi University, 06500 Ankara, Turkey \\ ${ }^{\mathrm{c}}$ Department of Economics, TED University, 06440 Ankara, Turkey
}

\section{A R T I C L E I N F O}

\section{Article history:}

Received 11 March 2012

Available online 10 May 2012

\section{Keywords:}

Inflation

Inflation uncertainty

Stochastic volatility models

\begin{abstract}
A B S T R A C T
This paper aims to investigate the direct relationship between inflation and inflation uncertainty by employing a dynamic method for the monthly country-region-place United States data for the time period 1976-2007. While the bulk of previous studies has employed GARCH models in investigating the link between inflation and inflation uncertainty, in this study Stochastic Volatility in Mean models are used to capture the shocks to inflation uncertainty within a dynamic framework. These models allow researchers to assess the dynamic effects of innovations in inflation as well as inflation volatility on inflation and inflation volatility over time, by incorporating the unobserved volatility as an explanatory variable in the mean (inflation) equation. Empirical findings suggest that innovations in inflation volatility increases inflation. This evidence is robust across various definitions of inflation and different sub-periods.
\end{abstract}

(c) 2012 Elsevier B.V. All rights reserved.

\section{Introduction}

The uncertainty about future levels of inflation has been one of the most important costs of inflation, as it clouds the decision making of economic agents. The relationship between inflation and inflation uncertainty is important for policymakers because if systematic inflation has any real effects, governments can influence economic performance through monetary policy. There are two conflicting views concerning the relationship between inflation and inflation uncertainty. ${ }^{3}$ A number of theoretical models, where monetary policy often plays a prominent role, predict that uncertainty about future inflation is positively related with inflation. Similar to Refs. [3,4], who highlight the positive relationship between inflation and inflation uncertainty, Ref. [5] reports that inflation uncertainty will increase at higher rates of inflation due to the uncertainty concerning future monetary policy causes. Refs. [6,2,7] report evidence on this effect. Ref. [8], on the other hand, argue that an increase in inflation uncertainty leads to an increase in inflation as it provides an incentive to the policymaker to create an inflation surprise in order to stimulate output growth. Similarly, Ref. [9] claims that another factor contributing to the positive relationship between inflation and inflation uncertainty is that the timing of the disinflationary policy action is uncertain.

An alternative explanation for a positive relationship between inflation and inflation uncertainty is provided by Holland [1] who claims that inflation uncertainty increases at higher rates of expected inflation. In addition to the uncertainty

\footnotetext{
* Corresponding author. Tel.: +90 312290 2342; fax: +90 3122665140.

E-mail addresses: berument@bilkent.edu.tr (M.H. Berument), yyeliz@gazi.edu.tr (Y. Yalcin), julide.yildirim@tedu.edu.tr (J. Yildirim). URLs: http://www.bilkent.edu.tr/ berument/ (M.H. Berument), http://yyelizyalcin.googlepages.com/ (Y. Yalcin).

1 Tel.: +90 312216 1304; fax: +90 3122132036 .

2 Tel.: +90 312418 4147; fax: +90 3124184148 .

3 See Refs. [1,2] for review of the literature.
} 
of the impact of monetary policy on inflation, the speed with which monetary policy actions are transmitted to inflation varies over time. Thus, even though the agents have all the information regarding the stance of monetary policy, the complexity of predicting the magnitude and the speed with which prices will respond to monetary policy creates inflation uncertainty.

The second view promotes the causation that runs from inflation uncertainty to inflation. Refs. $[8,10]$ argue that if the money supply process has a stochastic element and the public is uncertain about the objective function of the policymaker, higher inflation uncertainty raises the optimal inflation rate by increasing the incentive for the policy maker to create inflation surprise to stimulate real economic activity within the traditional Barro-Gordon framework.

Since the measurement of the inflation uncertainty is subjective, generally proxy variables are employed. Following the seminal paper of Ref. [11] on Autoregressive Conditional Heteroskedasticity (ARCH) models and the subsequent Generalized Autoregressive Conditional Heteroscedasticity (GARCH) extension by Bollerslev [12], inflation uncertainty is generally proxied by the conditional variance of unanticipated shocks as well as the lag values of squared residuals for inflation. ${ }^{4}$ Generally, empirical studies report mixed evidence regarding the association between inflation and inflation uncertainty using a variety of methodologies. One of the common features reported in empirical analysis is that these studies usually examine the inflation-inflation uncertainty relationship at either short run or long-run horizons. However, Ref. [16] argue that this relationship may differ between short-run and long-run horizons. In order to capture the inflation-inflation uncertainty relationship within long and short run horizons a dynamic framework should be employed where this relationship is further assessed with the impulse response analyses. Accordingly, as an alternative to GARCH models that capture this time-varying autocorrelated volatility process, the Stochastic Volatility (SV) models have been employed to explain the well documented time varying volatility in empirical research. Unlike ARCH/GARCH models, SV models allow for a stochastic element in the time series evolution of the conditional variance process. ${ }^{5}$ Refs. $[20,21]$ provide empirical evidence supporting the successes of the log-normal SV model relative to GARCH-type models.

This paper aims to investigate the direct relationship between inflation and inflation uncertainty for the United States over the period 1976-2007 using monthly data. Unlike the existing literature where the inflation uncertainty is generally proxied by ARCH/GARCH models, inflation uncertainty in this study is modeled by SV model with state space approach to capture the shocks to inflation volatility and assess the effect of inflation and inflation volatility shocks on inflation and inflation volatility within a dynamic framework. This paper is organized as follows. Section 2 presents the modeling approach employed in this study. Estimation results are reported in Section 3. Finally, Section 4 concludes.

\section{Model}

There are two general classes of volatility models that have been employed in the time series literature to capture uncertainty: the GARCH and the SV models. The GARCH models formulate the conditional variance directly as a function of observables. Whereas the variance in the SV model is modeled as an unobserved component, it follows some stochastic process. These might be called latent volatility or SV models. The most general form of mean equation for both models can be described as follows

$$
\begin{aligned}
& \pi_{t}=\mu_{t}+\sigma_{t} \varepsilon_{t}, \quad \varepsilon_{t} \sim \operatorname{NID}(0,1) \\
& \mu_{t}=\alpha_{0}+\sum_{i=1}^{k} \alpha_{1 i} x_{i, t}
\end{aligned}
$$

where $\pi_{t}$ is the dependent variable (inflation), $\mu_{t}$ is the mean, $x_{i, t}$ is a set of regressors at time $t, \alpha_{0}$ is a constant and $\alpha_{11}, \alpha_{12}, \ldots, \alpha_{1 k}$ are regression coefficients. The disturbance term $\varepsilon_{t}$ is independently and identically normally distributed with zero mean and unit variance. Accordingly, the mean adjusted series can be defined as white noise with unit variance multiplied by the volatility process. SV models consider that the unknown volatility changes stochastically over time. They contain an unobserved variance component, the logarithm of which is modeled directly as a linear stochastic process, such as an autoregression. This feature of the SV models can be regarded as an alternative to the GARCH models, which have relied on simultaneous modeling of the first and second moment.

A common notation for the variance equation of the SV class of volatility models is given by

$$
\sigma_{t}^{2}=\sigma^{* 2} \exp \left(h_{t}\right)
$$

where $\sigma^{*}$ is a positive scaling factor.

The volatility process $\sigma_{t}^{2}$ is defined as the product of a positive scaling factor $\sigma^{*}$, and the exponential of the stochastic process $h_{t}$. Assume that $h_{t}=\ln \left(\sigma_{t}^{2} / \sigma^{* 2}\right)$ follows an autoregressive model of order one as in

$$
h_{t}=\beta_{1} h_{t-1}+\sigma_{\eta} \eta_{t}, \quad \eta_{t} \sim \operatorname{NID}(0,1)
$$

\footnotetext{
4 For surveys on GARCH models please see Refs. [13-15].

5 For surveys of SV models, see among others [17-19].
} 
for the stationarity of $\sigma_{t}^{2}$, the persistence parameter $\left(\beta_{1}\right)$ is restricted to be less than one in a absolute value $\left(\left|\beta_{1}\right|<1\right){ }^{6}$ It is assumed that the disturbances $\varepsilon_{t}$ and $\eta_{t}$ are mutually uncorrelated contemporaneously and at all lags. Since the term ln $\sigma^{* 2}$ can be regarded as the constant term in the logarithm of volatility equation $\left(h_{t}\right)$, the logarithm of volatility process does not include an additional intercept term. SV model can be rewritten as follows:

$$
\begin{aligned}
\ln \sigma_{t}^{2} & =\ln \sigma^{* 2}+h_{t} \\
& =\ln \sigma^{* 2}+\beta_{1}\left(\ln \sigma_{t-1}^{2}-\ln \sigma^{* 2}\right)+\sigma_{\eta} \eta_{t} \\
& =\left(1-\beta_{1}\right) \ln \sigma^{* 2}+\beta_{1} \ln \sigma_{t-1}^{2}+\sigma_{\eta} \eta_{t} .
\end{aligned}
$$

SV and GARCH models require simultaneous estimation of the conditional mean and variance equations (see Ref. [22]). GARCH models are deterministic in the sense that only the mean equation has a disturbance term and that its variance is modeled conditionally on the information up to and including time $t-1$. For the SV model, the deviation of $\pi_{t}$ from the mean is captured by a function of two disturbance terms whereas in the GARCH model this deviation is accounted for by a single disturbance term.

Ref. [23] extended the stochastic volatility model that allows the inclusion of the variance as one of the determinants of the mean -SV in Mean (SVM) model-where the mean equation is rewritten as follows:

$$
\mu_{t}=\alpha_{0}+\sum_{i=1}^{k} \alpha_{1 i} x_{i, t}+\alpha_{2} \sigma^{* 2} \exp \left(h_{t}\right)
$$

where $\alpha_{2}$ is a risk premium coefficient to capture the volatility-in-mean effect. We model the mean equation of inflation as an AR process which is parallel to Refs. [7,24] to capture the dynamics of inflation process in our case. Thus, the SVM model is defined in Eqs. (1), (3), (4) and (6) as follows

$$
\begin{aligned}
& \pi_{t}=\alpha_{0}+\sum_{i=1}^{k} \alpha_{1 i} \pi_{t-i}+\alpha_{2} \sigma^{* 2} \exp \left(h_{t}\right)+\sigma^{*} \exp \left(0.5 h_{t}\right) \varepsilon_{t}, \quad \varepsilon_{t} \sim \operatorname{NID}(0,1) \\
& h_{t}=\beta_{1} h_{t-1}+\sigma_{\eta} \eta_{t}, \quad \eta_{t} \sim \operatorname{NID}(0,1) .
\end{aligned}
$$

A variety of estimation procedures have been proposed for the SV models, including the Generalized Method of Moments [25], the Quasi Maximum Likelihood [26,27], the Efficient Method of Moments [28] and Markov-Chain Monte Carlo [29,30,21]. In this paper, the parameters of the SVM model are estimated by exact maximum likelihood methods using Monte Carlo importance sampling techniques. This method has three important advantages: (1) It exploits the structure of the specification to improve the speed of the convergence by integrating the Kalman Filter. (2) The dimension of state is increased by approximating the log likelihood (see Ref. [31], for details). (3) It can be extended to multivariate case by using multivariate Taylor series expansion. All these properties enable researchers to include explanatory variables in the mean equation and estimate their coefficients simultaneously with the parameters of the volatility process.

The likelihood function for the SV model can be constructed using simulation methods developed by Shephard and Pitt [31] and Durbin and Koopman [32]. Consider the standard SV model of the equation of the volatility process presented in Eq. (4). The non-linear relation between $\log$-volatility $h_{t}$ and the observation equation of $\pi_{t}$ does not allow the computation of the likelihood by linear methods such as the Kalman filter. The likelihood function for the SV model can be expressed as:

$$
L(\Psi)=p\left(\frac{\pi}{\Psi}\right)=\int p\left(\frac{\pi, \theta}{\Psi}\right) \mathrm{d} \theta=\int p\left(\frac{\pi}{\theta, \Psi}\right) p\left(\frac{\theta}{\Psi}\right) \mathrm{d} \theta
$$

where $\psi=\left(\alpha, \beta, \sigma_{\eta}, \sigma_{\varepsilon}\right)^{\prime}, \theta=\left(h_{1}, \ldots, h_{T}\right)^{\prime}$. An efficient way of evaluating such expressions is by using importance sampling (see Ref. [33]). A simulation device is required to sample from an importance density $\hat{p}(\pi / \theta, \psi)$, which is preferred to be as close as possible to the true density $p(\pi / \theta, \psi)$. A choice for the importance density is the conditional Gaussian density since in this case it is relatively straightforward to sample from $\hat{p}(\pi / \theta, \psi)=g(\pi / \theta, \psi)$ using simulation smoothers such as the ones developed by De Jong and Shephard [34] and Durbin and Koopman [35]. Guidelines for the construction of an importance model and the likelihood function for the SV model using this model are given by Hol and Koopman [36] and Asaf [37]. One may also look at Ref. [23] for more explanations. During the estimation process, we extended this model as $p$-th order SVM model and added lag variables of volatility-in-mean effect in mean equation, which can be presented as follows:

$$
\begin{aligned}
\pi_{t} & =\alpha_{0}+\sum_{i=1}^{p} \alpha_{1 i} \pi_{t-i}+\sum_{i=1}^{p} \alpha_{2 i} \sigma^{* 2} \exp \left(h_{t-i}\right)+\sigma^{*} \exp \left(0.5 h_{t}\right) \varepsilon_{t}, \quad \varepsilon_{t} \sim N I D(0,1) \\
h_{t} & =\sum_{i=1}^{p} \beta_{1 i} h_{t-i}+\sum_{i=1}^{p} \beta_{2 i} \pi_{t-i}+\sigma_{\eta} \eta_{t}, \quad \eta_{t} \sim N I D(0,1)
\end{aligned}
$$

\footnotetext{
6 As a part of robustness of the estimates, we also consider alternative stochastic volatility specifications that includes additional lags. However, Schwarz Bayesian Criteria suggest that the lag length is one.
} 
Table 1

Estimation results for SVM model.

\begin{tabular}{|c|c|c|c|c|}
\hline$\pi_{t}$ & $\begin{array}{l}\text { Constant } \\
0.1049 \\
{[-0.1386: 0.3485]}\end{array}$ & $\begin{array}{l}\pi_{t-1} \\
0.5073 \\
{[0.4974: 0.5349]}\end{array}$ & $\begin{array}{l}\sigma^{* 2} \exp \left(h_{t-1}\right) \\
1.0477 \\
{[-0.1002: 2.1955]}\end{array}$ & $\begin{array}{l}\exp \left(0.5 h_{t}\right) \varepsilon_{t} \\
0.0177 \\
{[0.0127: 0.0247]}\end{array}$ \\
\hline$h_{t}$ & $\begin{array}{l}h_{t-1} \\
0.9248 \\
{[0.9104: 0.9370]}\end{array}$ & $\begin{array}{l}\pi_{t-1} \\
0.1495 \\
{[0.0821: 0.216]}\end{array}$ & $\begin{array}{l}\eta_{t} \\
0.2568 \\
{[0.1715: 0.3844]}\end{array}$ & \\
\hline $\begin{array}{l}\ln L: 52.694 \\
Q(12): 0.0517(0.820 \\
\text { Normality test statist }\end{array}$ & $\begin{array}{l}\text { AIC: }-91.388 \\
01 \text { ) } \\
\text { stics of the standa }\end{array}$ & $\begin{array}{l}\text { SBC: }-63.788 \\
Q(24): 0.9846(0.3210) \\
\text { duals: } 1.073(0.5847)\end{array}$ & HQ: -22.189 & \\
\hline
\end{tabular}

Note: Numbers in parentheses and brackets are the $p$-values and confidence intervals at the $95 \%$, respectively. AIC, SBC and $\mathrm{HQ}$ are calculated, respectively, $-2(\ln \mathrm{L})+2 q,-2(\ln \mathrm{L})+q \ln (T)$ and $-2(\ln \mathrm{L})+2 q \ln (T)$. Where $q$ is the total number of estimated parameters, $T$ is the total number of observations.

$\mathrm{Q}(\mathrm{i})$ reports Wooldridge [39]'s robust LM test for $i$ lag and $p$-values are reported next to test statistics in parenthesis for $i$ th lag.

here the lag orders for each variable is set to $p$ to make the model symmetric so that the system resembles to a conventional VAR model in a nonlinear form. This model is estimated by using SsfPack package written in the Ox language by Koopman et al. [38]. ${ }^{7}$

\section{Empirical results}

In this study, seasonally adjusted monthly data of the United States Consumer Price Index for All Urban Consumers are used. This index series covers the period 1976:01-2007:09. ${ }^{8}$ Inflation is measured by the monthly difference of the logarithm of the consumer price index for all urban consumers. In order to explore the relationship between inflation and its volatility, in this study, SVM model as defined in Eqs. (8a) and (8b) are estimated jointly. Schwarz Bayesian Criteria (SBC) is used to determine the optimal lag lengths of the model; the lag order was one. Thus we took $p=1$ for Eqs. ( $8 \mathrm{a}$ ) and (8b). The SVM model estimates are reported in Table 1 . The parameters, which govern the mean process are presented in the first part of Table 1 together with their 95\% confidence intervals. The confidence intervals are reported in brackets under the corresponding parameters. The estimates of the volatility specification parameters, on the other hand, are presented in the second part. The estimated coefficient for the lagged inflation in the mean equation is statistically significant and both lag values of inflation and volatility measures are statistically significant in the volatility specification. Volatility persistence estimation for index series is less than 1 in absolute value $\left(\left|\beta_{1}\right|<1\right)$. Thus, we may claim that $h_{t}$ is stationary. ${ }^{9}$

Mean (inflation) specification includes lagged values of inflation and volatility of the inflation. Volatility specification includes the lagged values of the inflation volatility and inflation. The Table 1 suggests that the lagged value of inflation has an explanatory power for current volatility but the lagged values of volatility do not have statistically significant explanatory power for the inflation at the $5 \%$ level.

With regard to the distributional assumptions for the standardized error term $\left(\varepsilon_{t}\right)$ in Table 1, the presence of autocorrelation of the standardized residual is tested by using the LM test suggested by Wooldridge [39] for 12 and 24 periods. The hypothesis that the first 12 and 24 autocorrelation coefficients of $\varepsilon_{t}$ are equal to zero cannot be rejected at the $5 \%$ significance level. Moreover, the Jarque-Berra Normality test statistic is smaller than the critical $\chi_{2}^{2}$ value at the $5 \%$ level of confidence. Thus, the null hypothesis of normally distributed disturbances cannot be rejected, supporting the validity of model specification.

Impulse responses

In order to explore the effect of inflation and inflation volatility shocks on inflation volatility and inflation, we calculated the Generalized Impulse (GI) Responses following to Ref. [40]. Yet calculating these impulse responses is not a straight forward task for nonlinear models. This section outlines the gathering of these impulse responses.

Let a nonlinear Markov multivariate model of order $p$ be defined as

$$
Y_{t}=F\left(Y_{t-1}, \ldots, Y_{t-p}\right)+H_{t} V_{t}
$$

where $F(\cdot)$ is a known function, $Y_{t}$ is a $K \times 1$ random vector, $V_{t}$ is $K \times 1$ vector of $I I D$ random disturbances, $H_{t}$ is a $K \times K$ random matrix, and the shocks $V_{t}$ have zero means and finite variance. In the literature, there are various methods to calculate the impulse responses. However, we treat the baseline for the impulse response functions which are then defined as the conditional expectations given only the history. When we report the impulse responses, we report the GI responses for the case of an arbitrary current shocks, $v_{i t}$, and history, $\Omega_{t-1}$, where impulse responses are insensitive to the ordering of

\footnotetext{
7 The package is downloadable from http://sites.google.com/site/yyelizyalcin/.

8 The data was obtained from FRED of St Louis Fed: http://research.stlouisfed.org/fred2.

9 Since the system is non-linear, we also use Monte Carlo simulations for the stability of system. None of the forecast values of $\pi_{t}$ and $h_{t}$ are explosive, indicating that the system is stable.
} 
Effects of inflation shock on inflation

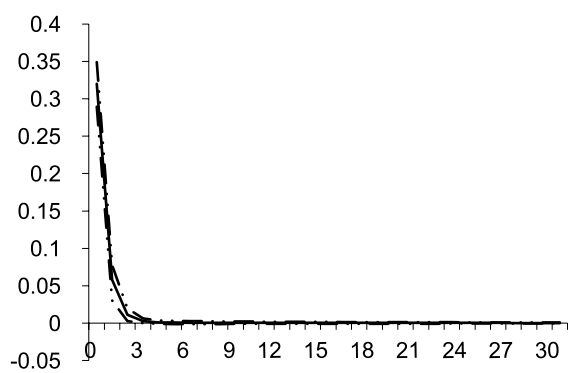

Effects of inflation volatility shock on inflation

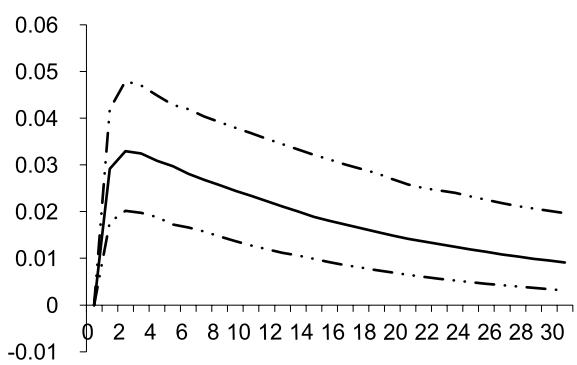

Effects of inflation shock on inflation volatility

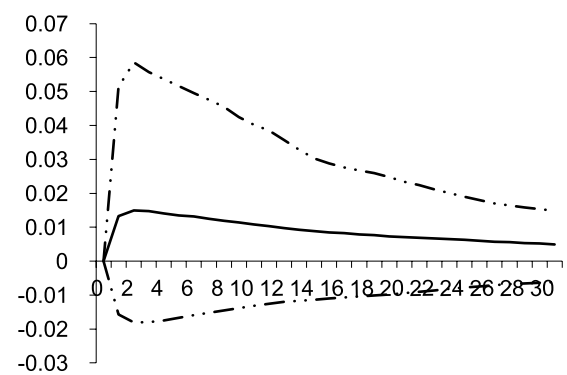

Effects of inflation volatility shock on inflation volatility

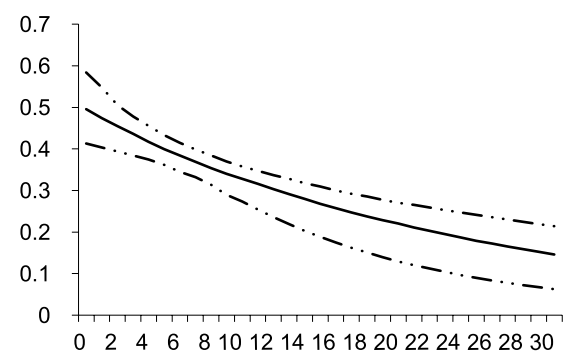

Fig. 1. Consumer Price Index for All Urban Consumers (All Items): 1976:01-2007:09.

variables because during the estimation process $\varepsilon_{t}$ and $\eta_{t}$ are mutually contemporaneously uncorrelated error terms at all lags; hence $H_{t}$ is diagonal (see Refs. [40,41]). The authors define $n$ period ahead Generalized Impulses to be conditional on history at given time $t-1$ and a $v_{i t}$ unit shock that is introduced at time $t$ for variable $i$.

$$
G I_{Y}\left(n, v_{i t}, \Omega_{t-1}\right)=E\left[Y_{t+n} \mid V_{i t}=v_{i t}, \Omega_{t-1}\right]-E\left[Y_{t+n} \mid \Omega_{t-1}\right] .
$$

Here $E\left[Y_{t+n} \mid V_{i t}=v_{i t}, \Omega_{t-1}\right]$ represents the expectations conditional on the information set $\Omega_{t-1}$ that is the set containing information used to forecast $Y_{t}$ and for a fixed value of the $i$ th variable shock at time $t$, while averaging out the effects of the other shocks at time $t$ given its value, $v_{i t}$. Similarly, $E\left[Y_{t+n} \mid \Omega_{t-1}\right]$ is the conditional expectation on the information set $\Omega_{t-1}$ with the latter term capturing the benchmark value where the economy has not been subject to any shocks. Thus, we compare the two state of the world where we had a shock for only one variable at time $t$ and compare it to the state of the economy is not subject to any shock. ${ }^{10}$

As a mean of statistical inference for the impulse response analysis, the $95 \%$ confidence intervals based on the bootstrap simulation with 250 trials are calculated. After estimating the relationship between inflation and inflation volatility, the impulse responses of inflation and inflation volatility when a unit shock is given for $\varepsilon_{t}$ and $\eta_{t}$ for each four impulse responses along with 95\% confidence intervals for CPI for all urban consumers are plotted out in Fig. 1 . The history dependent impulse responses are reported for 30 periods, as the middle line, representing the median of the draws, and upper and lower (dotted) lines are for confidence intervals. The upper-left corner of the figure reports the impulse response for the effect of inflation shock to inflation and lower-right one reports effect of inflation volatility shock to inflation volatility. They suggest that inflation shocks are not persistent but shock to inflation volatility persist for 30 periods that we consider. Upper-right part of the Fig. 1 suggests that a shock to inflation increases inflation volatility, however, this effect is not statistically significant. Lower-left panel suggests that shock to inflation volatility increases inflation. It reaches its peak at the -0.03297 , in the 2 nd period but it is always positive and statistically significant for 30 periods. ${ }^{11}$ Note that the

\footnotetext{
10 As discussed in Refs. [40,42], multivariate nonlinear models have some problems like history and shock dependence. Thus, the impulse responses are going to be different for 1970:01 from the ones for 1990:01; the magnitude of a shock may give different results on persistency, or direction of impulse responses. In order to calculate impulse response; we gave one unit shock to standardized residuals of $\varepsilon_{t}$ and $\eta_{t}$. We also employ the averaging method of Ref. [43] for GI Responses. Their method uses the baseline forecasts (that is $E\left[Y_{t+n} \mid \Omega_{t-1}\right]$ ) that was conditional on information up to time $t$ and mean of these forecast are taken for the baseline; under stationarity they were unconditional means. When we introduce the unit shock to these two series, then averages across these histories until 2007:09 are than compared the mean of baseline forecasts.

11 Note that the residual term in the inflation volatility specification has zero mean and unit variance. However, the coefficient of $\eta_{t}$ is not necessarily equal to one. So one unit shock to $\eta_{t}$ actually means (depending on $\sigma_{\eta}$ ) one standard deviation shock to $\sigma_{\eta} \eta_{t} ; 0.2568$ unit shock to inflation volatility increases inflation it reaches its peak at 0.03297 in the 2 nd period.
} 
Effects of inflation shock on inflation

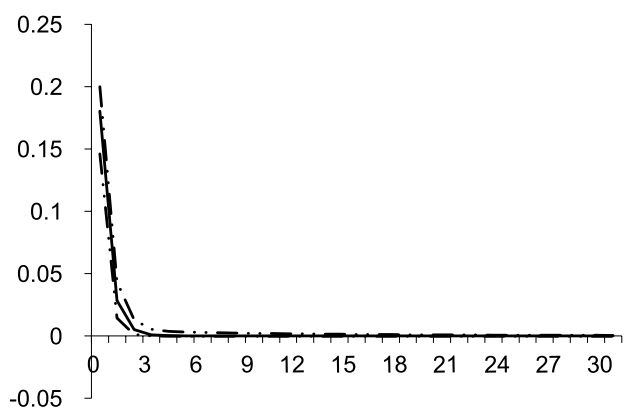

Effects of inflation volatility shock on inflation

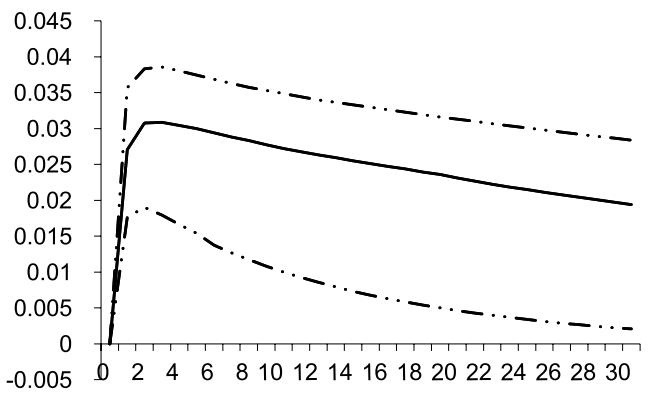

Effects of inflation shock on inflation volatility

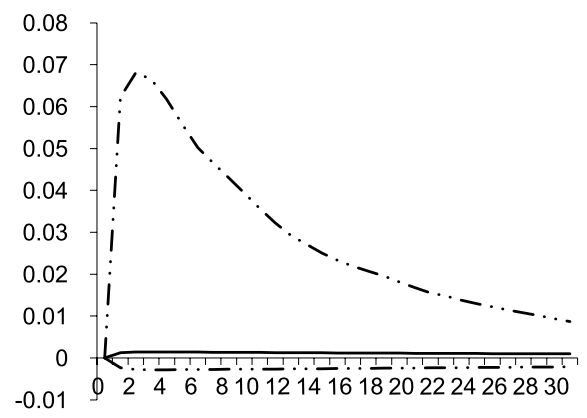

Effects of inflation volatility shock on inflation volatility

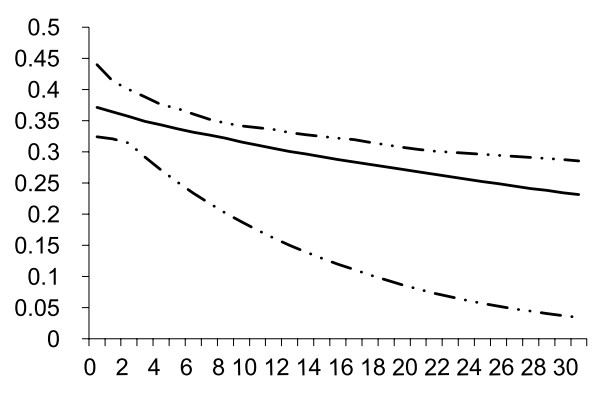

Fig. 2. CPI for all Urban Consumers (All Items Less Food \& Energy): 1976:01-2007:09.

effect of inflation volatility shock on inflation has a hump shape. However, at time $t+1$, due to higher inflation and volatility at time $t, \pi_{t+1}$ increases and the accelerating effect of one unit shock on $\eta_{t}$ will persist at $t+2$ then its effect will diminish.

After observing the positive effect of inflation volatility shock on inflation, in order to investigate the robustness of the results, four alternative measures of inflation are used. These alternative measures use (i) Consumers: All Items Less Food and Energy, (ii) Consumer Price Index Research Series Using Current Methods (CPI-U-RS), ${ }^{12}$ (iii) Personal Consumption Expenditures: Chain-type Price Index and (iv) Personal Consumption Expenditures Chain-Type Price Index Less Food and Energy. Figs. 2-5 report impulse responses similar to one reported in Fig. 1. Even though the effect of inflation shock on inflation volatility changes signs, it is not statistically significant. However, the effect of inflation volatility to inflation is robust, thus confirming the basic result from Fig. 1.

As a second set of robustness test, alternative time spans are considered for the benchmark inflation definition: United States Consumer Price Index for All Urban Consumers. Figs. 6 and 7 report the impulse responses for two different sample periods. The first sample uses the data for the post Korean War (1955:01-2007:09) and the second sample uses data for the post Volcker (Greenspan and Bernanke) era (1987:08-2007:09). For the first sub sample, the effect of inflation shock on inflation volatility is negative (not positive as in the benchmark sample 1976:01-2007:09) but not statistically significant as in the benchmark sample. Moreover, similar to the estimates on other impulse responses, the estimates on the effect of inflation volatility on inflation are robust. For the 1987:08-2007:09 sub-samples, evidence on both inflation shock on inflation volatility and inflation volatility shock on inflation are not statistically significant.

In order to assess the robustness of our inferences, we estimate different SVM specifications for the inflation and inflation volatility by using different lag orders for different inflation definitions and sub-periods. Among these estimates, various lags of inflation and its volatility are allowed to enter the mean (inflation) specification as well as the various lags of inflation and its volatility being allowed to enter the volatility specification. Even if these specifications are not suggested by SBC, the impulse responses for these specifications are calculated. Some of the impulse responses were explosive; this could mean that these specifications were not realistic. For the remaining impulse responses, the empirical evidence suggests that inflation volatility increases inflation, which is parallel to Ref. [8]. These estimates and corresponding impulse responses are not reported here but are available from the authors upon request.

\footnotetext{
12 The observations on CPI-RS ends 2006:12 due to data availability.
} 
Effects of inflation shock on inflation

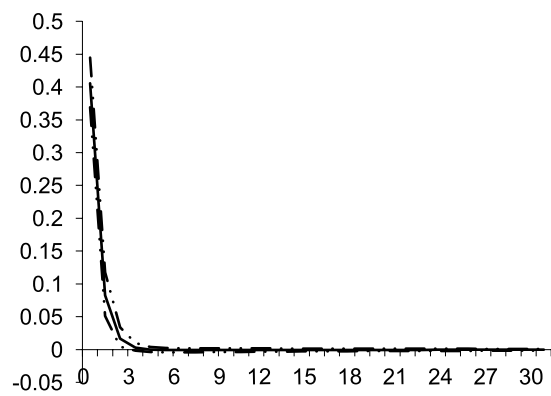

Effects of inflation volatility shock on inflation

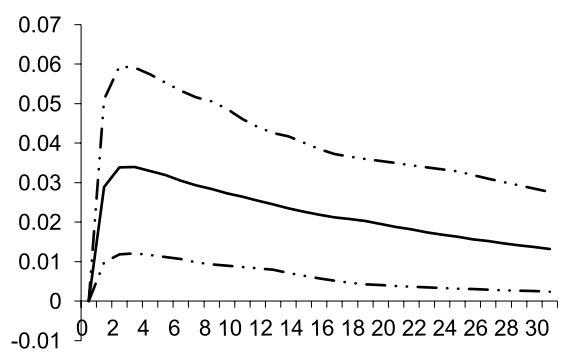

Effects of inflation shock on inflation volatility

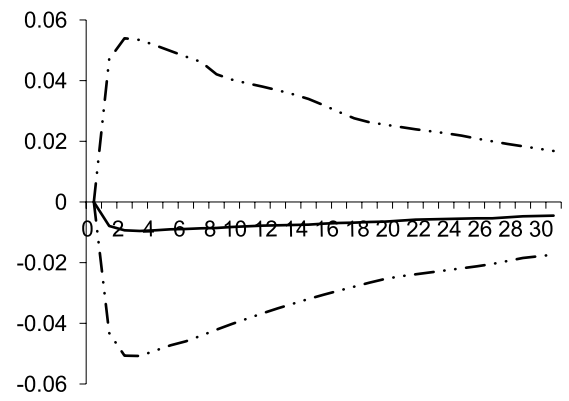

Effects of inflation volatility shock on inflation volatility

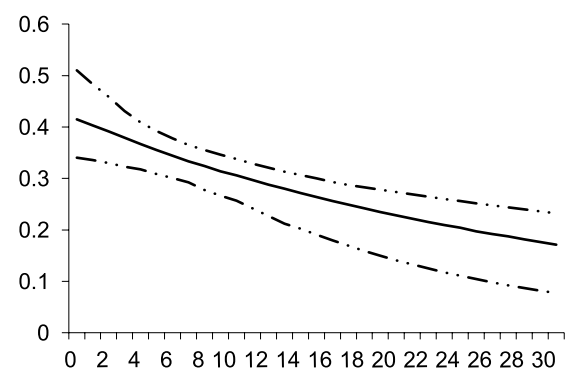

Fig. 3. Consumer Price Index Research Series Using Current Methods (CPI-U-RS): 1978:01-2006:12.

Effects of inflation shock on inflation

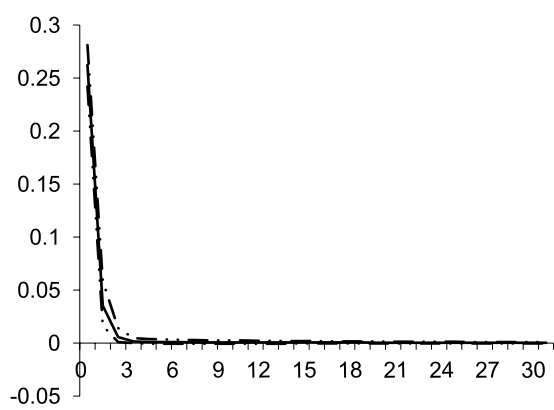

Effects of inflation volatility shock on inflation

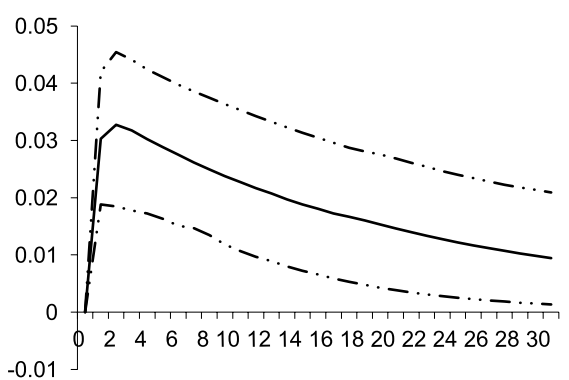

Effects of inflation shock on inflation volatility

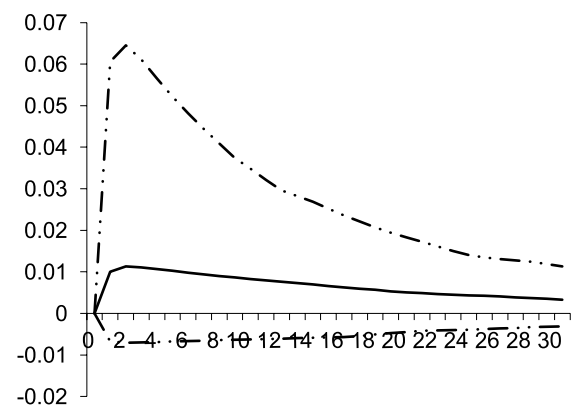

Effects of inflation volatility shock on inflation volatility

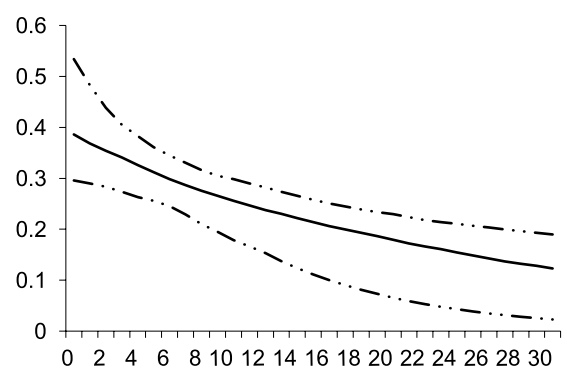

Fig. 4. Personal Consumption Expenditures (Chain-Type Price Index): 1976:01-2007:09. 
Effects of inflation shock on inflation

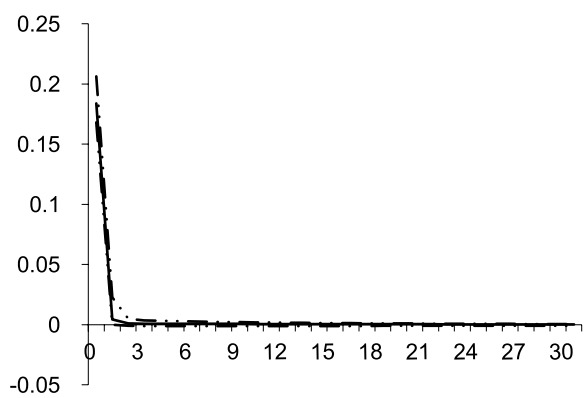

Effects of inflation volatility shock on inflation

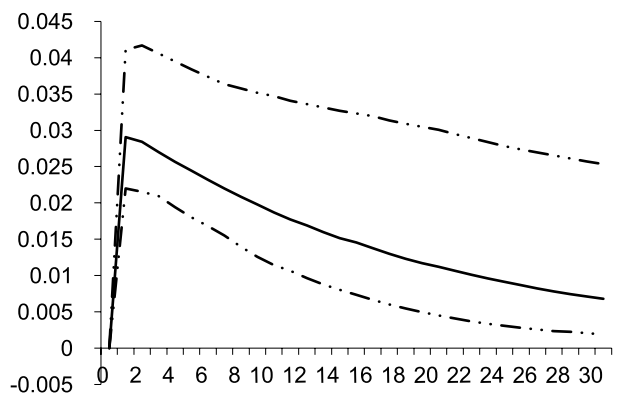

Effects of inflation shock on inflation volatility

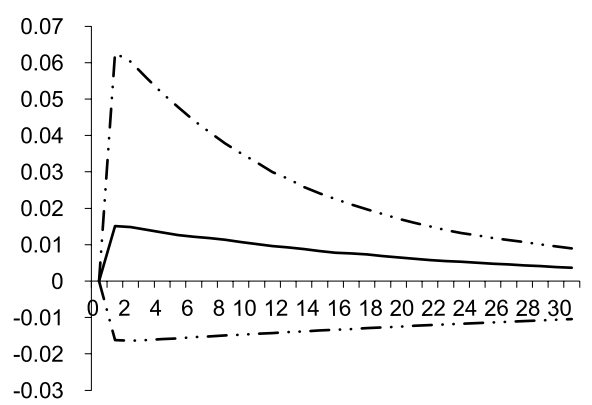

Effects of inflation volatility shock on inflation volatility

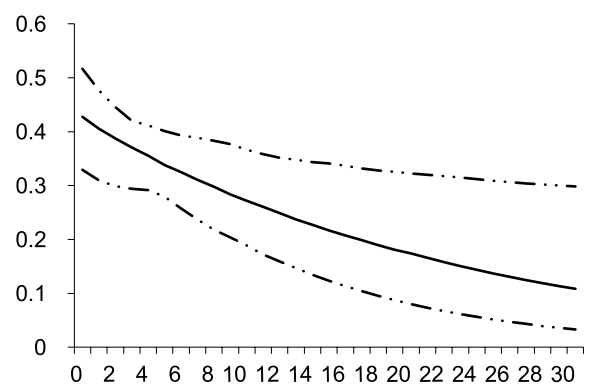

Fig. 5. PCE Chain-Type Price Index Less Food and Energy: 1976:01-2007:09.

Effects of inflation shock on inflation

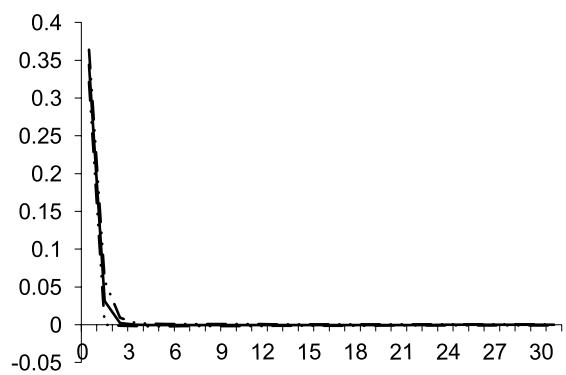

Effects of inflation volatility shock on inflation

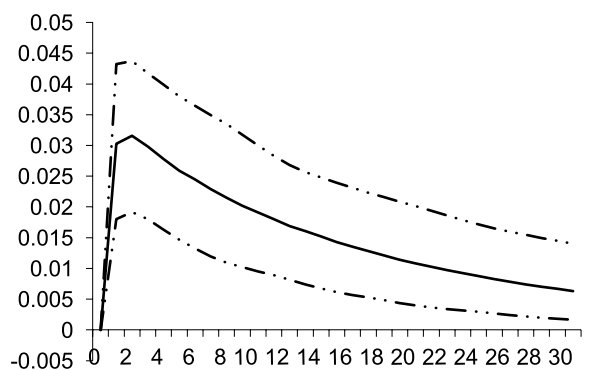

Effects of inflation shock on inflation volatility

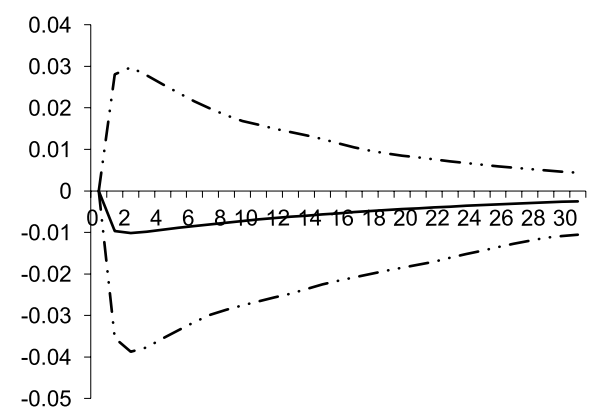

Effects of inflation volatility shock on inflation volatility

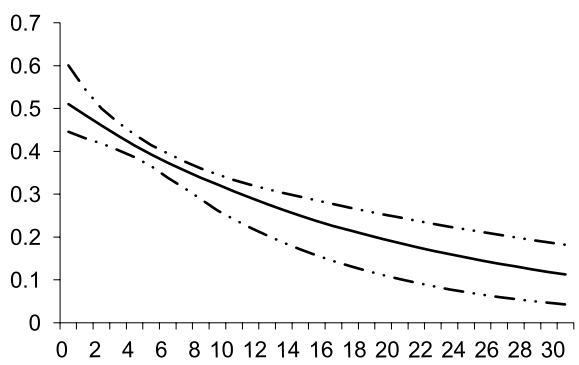

Fig. 6. Consumer Price Index for All Urban Consumers (All Items): 1955:01-2007:09. 
Effects of inflation shock on inflation

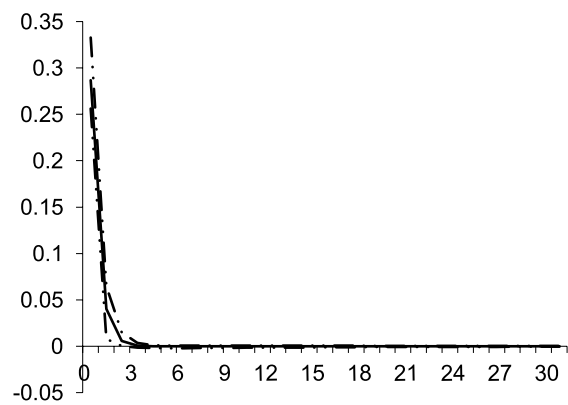

Effects of inflation volatility shock on inflation

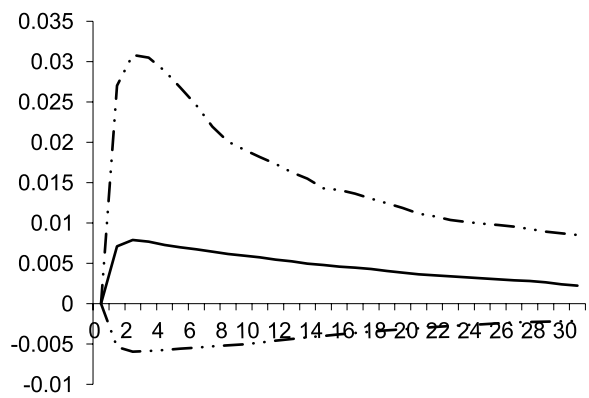

Effects of inflation shock on inflation volatility

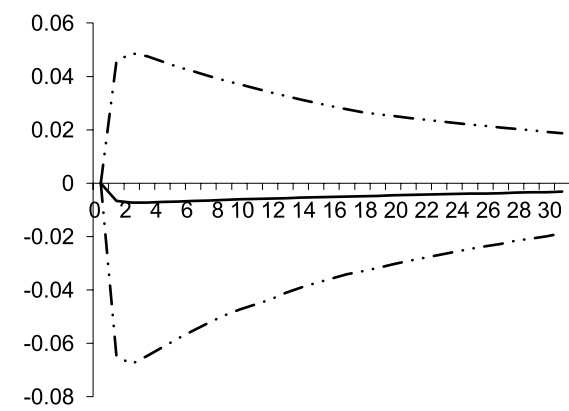

Effects of inflation volatility shock on inflation volatility

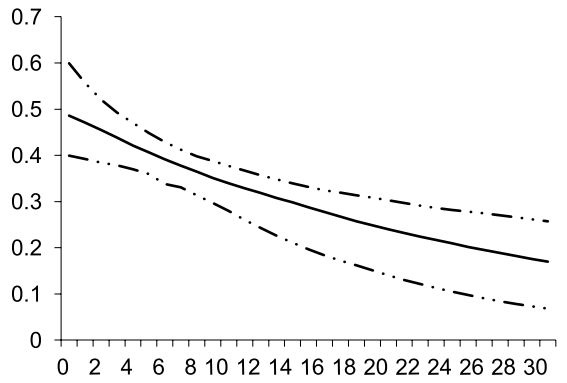

Fig. 7. Consumer Price Index for All Urban Consumers (All Items): 1987:08-2007:09.

The empirical results suggest that the effect of inflation on inflation volatility is unstable (sometimes positive and sometimes negative) but the effect of inflation volatility on inflation is mostly robust. ${ }^{13}$

Our model has similar features to Ref. [44] unobserved component trend-cycle with stochastic volatility model (UC-SV). They model the inflation with two components to allow trend change: permanent and transitory components. Both of these components have stochastic volatility. On the other hand, in our case we explicitly allow the inflation volatility affect the inflation (with a lag) and had one stochastic term. Nevertheless, both models suggest that inflation is affected by volatility changes.

Although ARCH types of models do not allow us to introduce shocks to the volatility, Engle type ARCH models are also considered in this analysis. Accordingly, volatility is specified as $\operatorname{GARCH}(1,1)$ in mean process where inflation is modeled with a constant term, its lag and the conditional variance of inflation. Fig. 8 reports both the volatility measures and inflation series itself. Both volatility measures indicate a low inflation volatility around 1990s, and there has been an increase after 2005. Even if both volatility measures move very closely, Fig. 8 suggests that SV measure lead GARCH $(1,1)$ specification. ${ }^{14}$

\section{Conclusion}

Even though the relationship between inflation and inflation uncertainty has been a topic of considerable interest, there is not a general agreement about the nature of the relationship at both the theoretical and empirical levels. Moreover, this relationship may differ between short-run and long-run horizons. However, previous studies on this issue generally have employed GARCH models without attempting to a dynamic modelling. This paper attempts to investigate the relationship between inflation and inflation volatility in a dynamic framework by using the United States monthly data from 1976:01 to 2007:09. The stochastic volatility in mean model, where the mean is modeled simultaneously with the volatility equation, is extended to construct measures of monthly inflation uncertainty. Empirical evidence from the impulse responses suggests that shock to inflation volatility increases inflation, confirming the findings of Refs. $[8,10]$. This effect appears to be robust to various specifications, such as the particular measure of inflation and alternative sample periods.

\footnotetext{
13 In order to make more informative inferences for the impulse responses, we had to calculate the confidence band, however, calculating these confidence bands with bootstrap method is expensive; 250 iterations take 4-5 days for the post 1976 sample with a Intel (R) Pentium (R) M1.73 GHz. Therefore, we did not calculate the confidence bands.

14 We also estimate the conditional variance with EGARCH in mean specifications, the basic result was robust.
} 


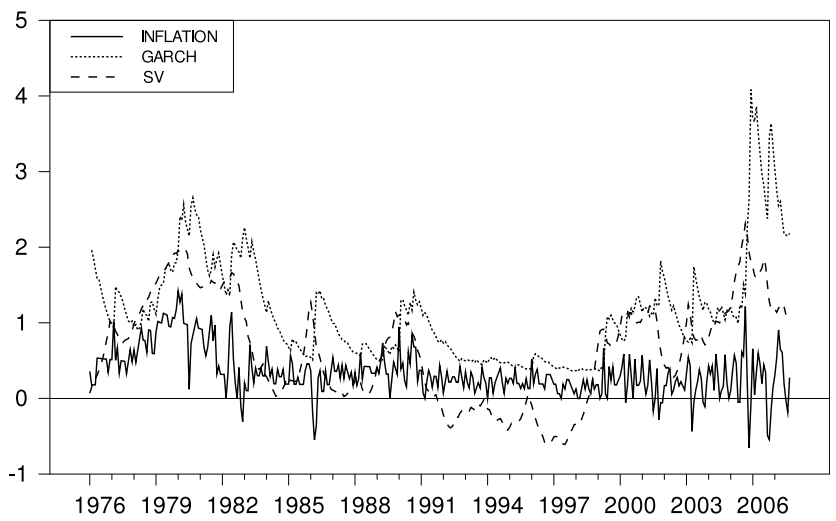

Fig. 8. Inflation, and stochastic volatility in mean and $\operatorname{GARCH}(1,1)$ in mean specifications of volatility.

\section{Acknowledgments}

We would like to thank to Yilmaz Akdi, Manabu Asai, and Nezir Kose for their valuable comments, The Turkish Scientific and Technological Research Council for their partial financial support (SOBAG-105K006) and Furkan Emirmahmutoglu for the excellent research assistance. We are also grateful to Pok-sang Lam for his sincere and well thought constructive comments.

\section{References}

[1] S. Holland, Comment on inflation regimes and the sources of inflation uncertainty, Journal of Money, Credit, and Banking 25 (1993) $514-520$.

[2] K. Grier, M.J. Perry, On inflation and inflation uncertainty in the G7 countries, Journal of International Money Finance 17 (1998) 671-689.

[3] A. Okun, The mirage of steady inflation, Brookings Papers on Economic Activity 2 (1971) 485-498.

[4] M. Friedman, Nobel lecture: inflation and unemployment, Journal of Political Economy 85 (1977) 451-472.

[5] L. Ball, Why does high inflation raise inflation uncertainty? Journal of Monetary Economy 29 (1992) 371-388.

[6] A.D. Brunner, G. Hess, Are higher levels of inflation less predictable? a state-dependent conditional heteroskedasticity approach, Journal of Business and Economic Statistics 11 (1993) 187-197.

[7] K. Grier, M.J. Perry, The effects of real and nominal uncertainty on inflation and output growth: some GARCH-M evidence, Journal of Applied Econometrics 15 (1) (2000) 445-458.

[8] A. Cukierman, A. Meltzer, A theory of ambiguity credibility and inflation under discretion and asymmetric information, Econometrica 54 (1986) $1099-1128$.

[9] J.E. Golob, Does inflation uncertainty increase with inflation, Federal Reserve Bank of Kansas City Economic Review 79 (1994) 27-38.

[10] A. Cukierman, Central Bank Strategy, Credibility and Independence: Theory and Evidence, MIT Press, Cambridge, Mass, 1992.

[11] R. Engle, Autoregressive conditional heteroscedasticity with estimates of the variance of UK inflation, Econometrica 50 (1982) 987-1008.

[12] T. Bollerslev, Generalized autoregressive conditional heteroskedasticity, Journal of Econometrics 31 (1986) 307-327.

[13] A.K. Bera, M.L. Higgins, ARCH models: properties, estimation and testing, Journal of Economic Surveys 7-4 (1993) 305-366.

[14] T. Bollerslev, R.F. Engle, D.B. Nelson, ARCH Models, in: Handbook of Econometrics, vol. IV, North-Holland, Amsterdam, 1994.

[15] F.X. Diebold, J.A. Lopez, Modeling volatility dynamics, in: K.V. Hoover (Ed.), Macroeconometrics: Developments, Tensions and Prospects, Kluwer Academic Press, Boston, 1995, pp. 427-472.

[16] L. Ball, S.G. Cecchetti, Inflation and uncertainty at short and long horizons, Brookings Papers on Economic Activity I (1990) 215-254

[17] S.J. Taylor, Modelling stochastic volatility: a review and comparative study, Mathematical Finance 4 (1994) 183-204.

[18] E. Ghysels, A.C. Harvey, E. Renault, in: G.S. Maddala, C.R. Rao (Eds.), Stochastic Volatility, in: Handbook of Statistics, vol. 14, North-Holland, Amsterdam, 1996.

[19] N. Shephard, Statistical aspects of ARCH and stochastic volatility, in: D.R. Cox, D.V. Hinkley, O.E. Barndorff-Nielsen (Eds.), Monographs on Statistics and Applied Probability, in: Time Series Models in Econometrics, Finance and other Fields, vol. 65, Chapman and Hall, 1996, pp. 1-67.

[20] J. Danielsson, Stochastic volatility in asset prices, estimation with simulated maximum likelihood, Journal of Econometrics 64 (1994) 375-400.

[21] S. Kim, N. Shephard, S. Chib, Stochastic volatility: likelihood inference and comparison with ARCH models, Review of Economic Studies 65 (1998) 361-394.

[22] A. Pagan, A. Ullah, The econometric analysis of models with risk term, Journal of Applied Econometrics 3 (1988) 87-105.

[23] S.J. Koopman, E.H. Uspensky, The stochastic volatility in mean model: empirical evidence from international stock markets, Journal of Applied Econometrics 17 (2002) 667-689.

[24] H. Berument, Z. Kilinc, U. Ozlale, The missing link between inflation uncertainty and interest rates, Scottish Journal of Political Economy 52 (2) (2005) $222-241$.

[25] A. Melino, S.M. Turnbull, Pricing foreign currency options with stochastic volatility, Journal of Econometrics 45 (1990) $239-265$.

[26] A.C. Harvey, E. Ruiz, N. Shephard, Multivariate stochastic variance models, Review of Economic Studies 61 (1994) $247-264$.

[27] E. Ruiz, Quasi-maximum likelihood estimation of stochastic volatility models, Journal of Econometrics 63 (1994) 289-306.

[28] A.R. Gallant, D.A. Hsieh, G.E. Tauchen, Estimation of stochastic volatility models with diagnostics, Journal of Econometrics 81 (1997) $159-192$.

[29] E. Jacquier, N.G. Polson, P.E. Rossi, Bayesian analysis of stochastic volatility models (with discussion), Journal of Business and Economics Statistics 12 (1994) 371-389.

[30] T. Andersen, H. Chung, B.E. Sorensen, Efficient method of moments estimation of a stochastic volatility model: a Monte Carlo study, Journal of Econometrics 91 (1999) 61-87.

[31] N. Shephard, M. Pitt, Likelihood analysis of non-Gaussian measurement time series, Biometrika 84 (1997)653-667.

[32] J. Durbin, S.J. Koopman, Monte Carlo maximum likelihood for non-Gaussian state space models, Biometrika 84 (1997) 669-684.

[33] B. Ripley, Stochastic Simulation, Wiley, New York, 1987.

[34] P. De Jong, N. Shephard, The simulation smoother for time series models, Biometrika 82 (1995) 339-350.

[35] J. Durbin, S.J. Koopman, A simple and efficient simulation smoother for state space time series analysis, Biometrika 3 (2002) 603-616. 
[36] E. Hol, S.J. Koopman, Forecasting the variability of stock index returns with stochastic volatility models and implied volatility, 2000. http://www.timbergen.nl.

[37] A. Asaf, The stochastic volatility in mean model and automation: evidence from TSE, The Quarterly Review of Economics and Finance 46 (2006) 241-253.

[38] S.J. Koopman, N. Shephard, J.A. Doornik, Statistical algorithms for models in state space form using SsfPack 2.2, Econometrics Journal 2 (1999) $113-166$

[39] J.M. Wooldridge, On the applications of robust, regression-based diagnostics to models of conditional means and conditional variances, Journal of Econometrics 47 (1991) 5-46.

[40] G. Koop, M.H. Pesaran, S.M. Potter, Impulse response analysis in nonlinear multivariate models, Journal of Econometrics, Elsevier 74 (1) (1996) 119-147.

[41] M.H. Pesaran, Y. Shin, Generalised impulse response analysis in linear multivariate models, Economic Letters 58 (1998) 17-29.

[42] S. Potter, Nonlinear impulse response functions, Journal of Economic Dynamics \& Control 24 (2000) 1425-1446.

[43] A.R. Gallant, P.E. Rossi, G. Tauchen, Nonlinear dynamics structures, Econometrics 61 (1993) 871-908.

[44] J.H. Stock, M.W. Watson, Why has US inflation become harder to forecast? Journal of Money, Credit and Banking 39 (1) (2007) 3-33. 